\title{
Detection rate of ureteric stones with ultrasonography and relationship with grade of hydronephrosis
}

\author{
Pankaj Kafle \\ Lecturer, Department of Radiology and Imaging, Purwanchal University of Medical and Allied Science (PUCMAS), \\ Gothgaun, Morang, Nepal.
}

Background: Ultrasound scanning can serve as reliable, basic first line mode of imaging techniques in detecting ureteric stone in patients with hydronephrosis and grade them accordingly with or without need of other imaging techniques. Aims and Objective: To evaluate the relationship between the degree of hydronephrosis and the detection rates of ureteral stones with ultrasonography in computed tomography or intravenous urography proven cases of ureteric calculi. Materials and Methods: This was a prospective observational study involving 75 patients with computed tomography or intravenous urography diagnosis of ureteric calculi. Both kidneys were observed by ultrasonography to evaluate the intrarenal collecting systems for hydronephrosis. Thereafter, the ureters were evaluated in four different locations to find any stone. The hydronephrosis was graded as mild, moderate and severe according to the dilatation of the pelvic calyceal system with or without stones. Detection rate of ureteric calculi was then estimated. Results: A total of 75 cases were evaluated. Stones were clearly observed in 51 of $59(86.4 \%)$ patients with calyceal dilatation, whereas stones were detected in 9 of $16(56.3 \%)$ patients without dilatation $(p<0.05)$. Out of 75 patients, $38(50.7 \%)$ had stones in the ureterovesical junction, $12(16 \%)$ had stones in the proximal ureter, $5(6.7 \%)$ in the iliac cross, $5(6.7 \%)$ in distal ureter and $15(20 \%)$ were undetected. Out of 15 undetected stones, $8(13.6 \%)$ had calyceal dilatation and $7(43.8 \%)$ without calyceal dilatation. Conclusion: The ultrasonography detection rate of ureteral stones was high in patients with calyceal dilatation. The whole ureter should be scanned in patients with calyceal dilatation for detection of ureteral stones. Even when patients have no calyceal dilatation, it is still considered to be useful to scan the ureterovesical junction.

Key words: Computed Tomography, Hydronephrosis, Intravenous Urography, Ultrasonography, Ureteral stone

\section{INTRODUCTION}

Ureteral colic is a common complaint of patients presenting at emergency room and outpatient clinics. Obtaining a comprehensive medical history and performing a careful physical examination are valuable for making an accurate diagnosis of ureterolithiasis. However, imaging studies are required to differentiate this condition from other diseases and to determine the optimal initial management strategy. For this purpose, plain-film kidney-ureter-bladder (KUB) radiography,
Access this article online

Website:

http://nepjol.info/index.php/AJMS

DOI: 10.3126/ajms.v9i3.19303

E-ISSN: 2091-0576

P-ISSN: $2467-9100$ 
patients are exposed to more ionizing radiation in CT than in IVU. ${ }^{4}$

US is radiation free and doesn't require contrast medium, it is the modality of choice for the initial evaluation, especially for children and pregnant women. ${ }^{1,5}$ Furthermore, it is inexpensive, universally available, has acceptable sensitivity and specificity and is not affected by the renal functions. ${ }^{2,6,7}$ US is a safe imaging technique and can be performed at the patient's bedside. It has been mainly used to evaluate the presence and degree of hydronephrosis in patients suspected of having ureterolithiasis. ${ }^{8}$

However, the sensitivity of US for detection of ureteric stones has been reported to be from $58 \%$ to $95 \%$ when the presence of hydronephrosis has been used as the diagnostic criterion and hydronephrosis does not always show the presence of a ureteral stone. ${ }^{1,7,9-14}$ Recently, detection of a ureteral stone with US has been reported to be useful for diagnosing ureterolithiasis. ${ }^{1,2,13}$ When a ureteral stone is clearly observed on US, then the diagnosis is confirmed. ${ }^{1,2,11,13}$

There is wide variation in the detection rate of ureteric calculi in various parts of the world. There is no such study done till date in Nepal on the relationship between the degree of hydronephrosis with US detection rates of ureteric stones.

Therefore, the purpose of our study was to evaluate the ultrasonographic detection of ureteral calculi and compare the relationships with grade of hydronephrosis in patients with CT or IVU proven ureteric calculi.

\section{METHODS AND MATERIAL}

This was a prospective cross sectional study involving 75 patients (49 men, 26 women, age; 15-78 years) who were diagnosed with ureteric calculus by CT or IVU with no other medical problems. There were 73 cases confirmed by IVU and 2 cases confirmed by CT urography. These patients were further evaluated by US to detect ureteric calculus with relationship to grade of hydronephrosis.

There were no false $(+)$ and true (-) groups and only the detection rates with relation to the grade of hydronephrosis was calculated.

The US examinations were performed on a Samsung R7 system using a $3.5 \mathrm{MHz}$ abdominal probe. During the examination, the patient reclined supinely, with some rotation either to the right or left side to facilitate the evaluation as described elsewhere.
The localizations of ureteral stones are classified as; proximal ureter if between the ureteropelvic (UP) junction and iliac cross, iliac cross localized, distal ureter if between the iliac cross and ureterovesical (UV) junction and UV junction localized.

The degree of hydronephrosis is a continuum, although somewhat arbitrary designations of mild, moderate, and severe hydronephrosis are commonly used. ${ }^{16,17}$ The grade of hydronephrosis is classified as follows; mild pelvicalyceal system (PCS) dilatation: grade 1, moderate PCS dilatation without parenchymal loss: grade 2, severe PCS dilatation with parenchymal thinning: grade 3 hydronephrosis. ${ }^{17}$

The statistical analysis was carried out by using SPSS software package version 13.0 (SPSS Inc.,Chicago, IL, USA). Chi square test (continuity correction and Exact) used. P-value $<0.05$ was considered statistically significant. Patients with or without ureteric stones as detected on USG were plotted against the grade of hydronephrosis and Percentage charts were obtained.

\section{RESULTS}

Total 75 patients were included in the study with the documented history of ureteric stones. The age group included in the study was from 17-78 years. The detection of ureteral stones was found highest in the age group of $35-45$ years, followed by $25-35$ years. The detection rate of ureteric stones depending on their location was found to be highest in the VUJ (50.7\%) region, followed by proximal $(16 \%)$ region and iliac cross $(6.7 \%)$ and distal $(6.7 \%)$ location respectively.

\section{DISCUSSION}

The sensitivity of US for ureteric stones has been reported to be $37-64 \%$ in different articles, but it has also been reported that these rates rises to $74-95 \%$ in obstructed collecting systems. ${ }^{1,7,18-21}$

\begin{tabular}{|c|c|c|c|c|c|}
\hline \multirow[t]{2}{*}{ Locations } & \multicolumn{5}{|c|}{ Grade Of Hydronephrosis } \\
\hline & $\begin{array}{l}\text { No } \\
\text { HDN }\end{array}$ & Mild & Moderate & Severe & Total \\
\hline Proximal & & & 7 & 5 & 12 \\
\hline Iliac Cross & 1 & 2 & 1 & 1 & 5 \\
\hline Distal & & & 3 & 2 & 5 \\
\hline VUJ & 1 & 5 & 10 & 22 & 38 \\
\hline $\begin{array}{l}\text { Undetected } \\
\text { Stones }\end{array}$ & 3 & 4 & 7 & 1 & 15 \\
\hline Total & 5 & 11 & 28 & 31 & 75 \\
\hline
\end{tabular}

Asian Journal of Medical Sciences | May-Jun 2018 | Vol 9 | Issue 3 


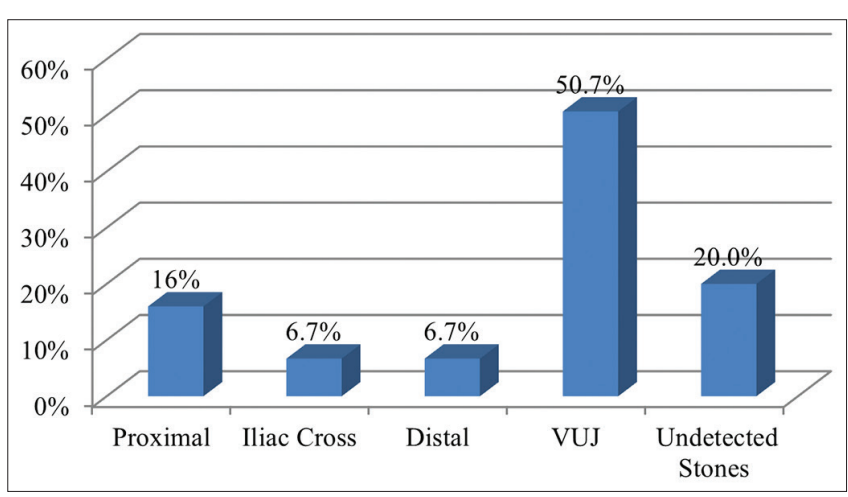

Figure 1: Correlation of HDN with different Locations of stone. Hydronephrosis was noted in majority of VUJ calculus than in other locations.

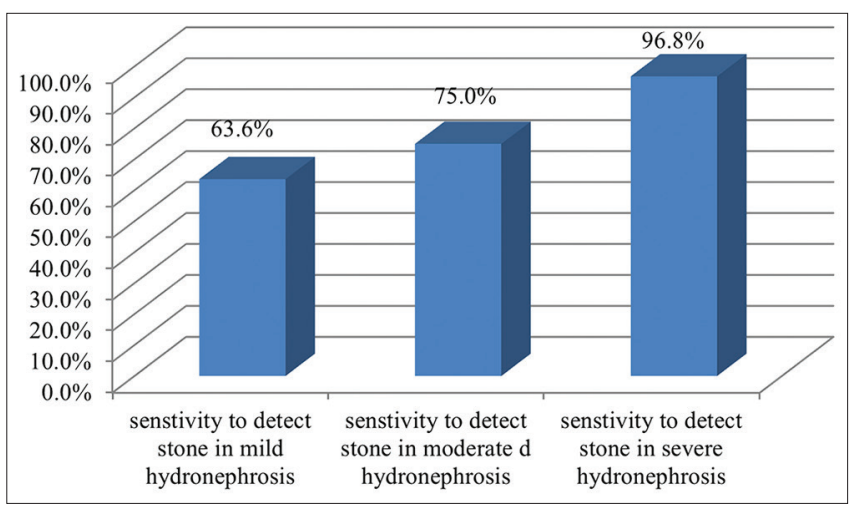

Figure 2: The sensitivity of USG for stone detection shows statistically significant difference between Mild and severe HDN. Detection rate of ureteral stones varied significantly from $63.6 \%-96.8 \%$ in mild and severe HDN respectively.


Figure 3: a) Shows right VUJ calculus and Fig b) Shows moderate dilatation of right pelvic-calyceal system and PUJ.

Sommer et al reported that they had high success rates for detecting ureteral stones by US when there is minimal hydronephrosis and that the false (-) rates are higher if there is no hydronephrosis. ${ }^{22}$ So one can mention that as the grade of hydronephrosis rises, the detection rate of ureteral stones with US also rises.

In our study, 60 out of 75 patients with ureteral stones were detected by US, giving a detection rate of $80 \%$. Detection rate of US raised from $63.6 \%$ for mild hydronephrosis (HDN) to $96.8 \%$ for severe HDN with ureteric stones. Detection rate for ureteric stones was found to be only $40 \%$ when there was no hydronephrosis. Our results are similar to those obtained by various other authors. ${ }^{23,24}$

In the study done by Kameda T.et.al, the ureteric stone detection rates were $73 \%$ with calyceal dilatation and $44 \%$ without dilatation. ${ }^{23}$ In another study by Özden E.et. al the detection rate of ureteric stones by USG in grade 1 hydronephrosis was $65.9 \%$, those with grade 2 hydronephrosis group was $78 \%$ and those with grade 3 hydronephrosis were $95 \%$. Such that detection of ureteric stone by USG was $73.9 \%{ }^{24}$

Our results showed more sensitivity of ultrasonography for the detection of ureteric calculi as compared to the studies done by Aslaksen et al. and Dalla et al. ${ }^{10,25}$

In a study conducted by Patlas et al showed $93 \%$ detection rate of ureteric stone and the detection rate of $\mathrm{HDN}$ was reported $100 \%{ }^{2}$ The results were satisfactory with the present study showing $80 \%$ detection rate of ureteric stone and $93.3 \%$ detection rate of $\mathrm{HDN}$.

Higher detection rate of ureteric calculi in our study could be due to advance in ultrasonographic technology or the awareness of the observer about the IVU or CT findings.

Saita et al determined the success rates of US according to the localization of the stone and they reported success rates of $82.2 \%$ in the proximal and $68 \%$ in the distal ureter. $^{26}$

In the present study the detection rates reported were $20 \%$ in the proximal ureter, $8.3 \%$ in the iliac cross and distal ureter and $63.3 \%$ in the VUJ region. The detection rate was highest in the VUJ region compared to the previous studies. This may be because the observer was aware of the $\mathrm{CT}$ and IVU findings.

There was a large difference in the detection rate of hydronephrosis with US in the previous studies reported by Aslaksen et al, Dalla et al, Yilmaz et al and Sheafor et al where the detection rates were lower, $74 \%, 73 \%, 73 \%$ and $65 \%$ respectively. ${ }^{10,25,11}$ However in studies reported by Patlas et al and Ripolles et al detection rates of hydronephrosis was $100 \%$, which was higher than that reported in the present study $(93 \%)^{2,13}$

Yilmaz et al reported that CT was found to be the best modality for depicting ureteral stones with an accuracy of $95 \%$, while IVU had $66 \%$ and US $45 \%$ accuracy values. ${ }^{11}$ But Patlas et al found US and spiral CT equally sensitive in detection of ureteral calculi with $93 \%$ and $91 \%$ sensitivity respectively. ${ }^{2}$ Our results are also comparable to that of CT findings when there is severe hydronephrosis. 


\section{CONCLUSION}

Ultrasonography has high detection rate of ureteric calculi. The detection rate is comparable to CT when there is presence of severe hydronephrosis. Even when patients have no calyceal dilatation, it is still considered to be useful to scan the VUJ.

US, as a noninvasive modality, should be the first imaging choice especially when there is hydronephrosis. Spiral CT can be reserved only for cases where US fails to provide adequate information. However, our results should be validated with further study involving large sample size.

\section{ACKNOWLEDGEMENT}

Radiology team of Purwanchal hospital.

\section{REFERENCES}

1. Sheafor DH, Hertzberg BS and Freed KS. Nonenhanced helical CT and US in the emergency evaluation of patients with renal colic, Prospective comparison 2000;217:792-797.

2. Patlas $M$, Farkas $A$ and Fisher $D$, Ultrasound vs $C T$ for the detection of ureteric stones in patients with renal colic. $\mathrm{Br} \mathrm{J}$ Radiol 2001; 74:901-904.

3. Evan AP, Coe FL, Lingeman JE, Shao Y, Sommer AJ and Bledsoe SB. Mechanism of formation of human calcium oxalate renal stones on Randall's plaque. Anat Rec (Hoboken) 2007; 290:1315-1323.

4. Whitfield HN. The management of ureteric stones part 1 diagnosis, BJU International. 84(1999) 911- 915.

5. Denton ER, Mackanzie A, Greenwell T, Popert R and Rankin SC. Unenhanced helical CT for renal colic: Is the radiation dose justifiable? Clin Radiol 1999; 54(7): 444- 447.

6. Boridy IC, Maklad N and Sandler CM. Suspected urolithiasis in pregnant women: Imaging algorithm and literature review. American Journal of Reontgenology 1996; 167 (4): 869- 875.

7. Erwin BC, Carroll BA and Sommer FG. Renal colic: The role of ultrasound in initial evaluation. Radiology 1984; 152:147-150.

8. Smith RC, Levine J, Dalrymple NC, Barish M and Arthur T Rosenfield. Acute flank pain: A modern approach to diagnosis and management, Seminars in Ultrasound CT Scan and MRI 1999; 20(2): 108-135.

9. Lanig FC, Jeffrey RB and Wing VW. Ultrasound versus excretory urography in evaluating acute flank pain. Radiology
1985;154: 613-616.

10. Aslaksen A and Go"thlin JH. Ultrasonic diagnosis of ureteral calculi in patients with acute flank pain. Eur J Radiol 1990; 11:87-90.

11. Yilmaz S, Sindel T and Arslan G. Renal colic: Comparison of spiral CT, US and IVU in the detection of ureteral calculi. Eur Radiol 1998; 8: 212-217.

12. Rosen CL, Brown DF and Sagarin MJ. Ultrasonography by emergency physicians in patients with suspected ureteral colic. J Emerg Med 1998;16: 865-870.

13. Ripolle's T, Agramunt $M$ and Errando J. Suspected ureteral colic: Plain film and sonography vs unenhanced helical CT. Eur Radiol 2004;14:129-136.

14. Kartal M, Eray $\mathrm{O}$ and Erdogru T. Prospective validation of a current algorithm including bedside US performed by emergency physicians for patients with acute flank pain suspected for renal colic. Emerg Med J 2006; 23: 341-344.

15. Middleton WD, Kurtz AB, Hertzberg BS. Ultrasound: The requisites. $2^{\text {nd }}$ ed. St Louis: Mosby, 2004; pp 103-51.

16. Swadan S, Mandavia D, Ma OJ, Mateer JR and Blaivas M. Emergency ultrasound, New York: McGraw Hill. (2008) 229-256.

17. Judith AW Webb, Cosgrove D, Meire H and Dewburry K. Abdominal and General Ultrasound 1993; 2:471.

18. Dahnert, Wolfgang Title: Radiology Review Manual, $6^{\text {th }}$ Edition Copyright (2007), Lippincott Williams \& Wilkins.

19. Deyoe LA, Cronan JJ and Breslaw BH. New techniques of ultrasound and color Doppler in the prospective evaluation of acute renal obstruction: Do they replace the intravenous urogram? Abdomen Imaging 1995; 20:58-63.

20. Sinclair D, Wilson $S$ and Toi $A$. The evaluation of suspected renal colic: Ultrasound scan versus excretory urography. Ann Emerg Med 1989;18:556-559.

21. Ellenbogen PH, Scheible FW and Talner LB. Sensitivity of gray scale ultrasound in detecting urinary tract obstruction. American Journal of Reontgenology 1978;130:731-733.

22. Palma LF, Stacul $F$ and Bazzocchi M. Ultrasonography and plain film versus intravenous urography in ureteric colic. Clin Radiol 1993; 47: 333-336.

23. Kameda T, Kawai F, Taniguchi N, Mori I, Ono M, Tsukahara N, et al. Ultrasonography for ureteral stone detection in patients with or without calyceal dilatation. J Med Ultrasonics 2010; 37:9-14.

24. Özden E, Karamürsel T, Göğüş C, Yaman O, Inal T and Göğüş O. Detection rate of ureter stones with US: Relationship with grade of hydronephrosis. J. Ankara Med School 2002;24:183-186.

25. Dalla PL, Stacul F and Bazzocchi M. Ultrasonography and plain film versus intravenous urography in ureteric colic. Clin Radiol 1993; 47:333-336

26. Saita $\mathrm{H}$, Matsukawa $\mathrm{M}$ and Fukushima $\mathrm{H}$. Ultrasound diagnosis of ureteral stones: Its usefulness with subsequent excretory urography. J Urol 1988;140:28- 31.

\footnotetext{
Authors Contribution:

PK-Concept and design of study, manuscript preparation, statistically analysed and interpreted with critical revision of manuscript.

Work attributed to:

Department of Radiology, Purwanchal university of medicine and allied science, Gothgaun, Morang, Nepal.

Orcid ID:

Dr. Pankaj Kafle- (i) http://orcid.org/0000-0001-7776-6555

Source of Support: Not Applicable., Conflict of Interest: None declared.
} 